\title{
Cigarette Filter Ventilation Blocking
}

National Cancer Institute

\section{Source}

National Cancer Institute. Cigarette Filter Ventilation Blocking. NCI Thesaurus. Code C122665.

A smoking behavior characterized by covering the filter ventilation holes on a cigarette with the fingers or lips while smoking. 